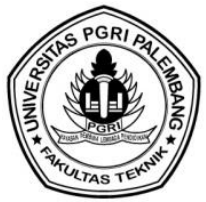

\title{
PENGARUH TEMPERATUR DAN UKURAN PARTIKEL TERHADAP DISTRIBUSI PRODUK PIROLISIS BATUBARA SUBBITUMINUS
}

\author{
Ratih Diah Andayani \\ Program Studi Teknik Mesin, Fakultas Teknik,Universitas IBA \\ Jl. Mayor Ruslan Palembang \\ ratihd.andayani@gmail.com
}

\begin{abstract}
ABSTRAK
Penelitian yang mengkaji kualitas air Sungai Cisadane Kota Tangerang berdasarkan Pemanfaatan batubara di Indinesia sebagai bahan bakar langsung mempunyai efek negatif terhadap lingkungan. Pirolisis merupakan teknologi yang dapat memberikan solusi guna mengoptimalkan pemanfaatan batubara yang aman terhadap lingkungan. Penelitian ini bertujuan mengkaji pengaruh temperatur dan ukuran partikel batubara terhadap distribusi produk pirolisis. Penelitian dilakukan di dalam reaktor unggun tetap bervolume 4 Liter dan tekanan atmosfer dengan menggunakan gas inert $\mathrm{N}_{2}$ pada laju alir tetap $300 \mathrm{~mL} /$ menit. Penelitian ini menggunakan batubara peringkat Sub-Bituminus B dari daerah penambangan Air Laya Bukit Asam Tanjung Enim Sumatera Selatan, dengan variasi temperatur dari $400{ }^{\circ} \mathrm{C}-700{ }^{\circ} \mathrm{C}$ ukuran partikel $-6 / 8$ mesh $(3,36-4,76 \mathrm{~mm})$ dan $-3 / 4$ mesh $(4,76-6,73 \mathrm{~mm})$. Hasil penelitian menunjukkan bahwa dengan kenaikan temperatur, produk zat terbang total dan gas terus meningkat hingga temperatur $700{ }^{\circ} \mathrm{C}$ sementara produk arang menurun. Produk tar menunjukkan kecenderungan meningkat dan mencapai maksimum pada temperatur $600{ }^{\circ} \mathrm{C}$ yaitu sebesar $20,03 \%$ dan $8,05 \%$ masing-masing untuk ukuran partikel $-6 / 8$ mesh dan $-3 / 4$ mesh, kemudian menurun pada temperatur $700{ }^{\circ} \mathrm{C}$. Ukuran partikel berpengaruh pada perolehan produk zat total dan tar. Pada ukuran partikel yang lebik kecil (-6/8 mesh) menunjukkan produk yang lebih tinggi dibanding hasil pada ukuran partikel yang lebih besar (-3/4 mesh), sementara pengaruh ukuran partikel terhadap produk gas tidak signifikan, sedangkan produk arang meningkat dengan bertambah besar ukuran partikel batubara yaitu sebesar $60,31 \%$ dan $62,16 \%$ masing-masing untuk ukuran partikel -6/8 mesh dan -3/4 mesh pada temperatur pirolsis $400^{\circ} \mathrm{C}$
\end{abstract}

Kata Kunci : pirolisis, temperatur, ukuran partikel,tar

\section{PENDAHULUAN}

Cadangan batubara di Indonesia sangat melimpah dibandingkan dengan minyak bumi, Kementerian ESDM mencatat cadangan total batubara Indonesiayang belum terjamah sebesar23,99 miliar tontahun 2017dengan jumlah cadangan yang terukur sebesar 8,24 miliar ton, dengan jumlah cadangan yang terbesar terdapat di Palu Sumatera dan Pulau Kalimantan dan sebagian kecil terdapat di Pulau Sulawesi, Papua dan pulau jawa.

Penggunaan batubara untuk keperluan dalam negeri Negeri (Domestic Market Obligation/DMO)terus mengalami peningkatan tercatat pada tahun 2013 pemanfaatan untuk DMO sebesar 72 juta ton, tahun 2014 sebesar 76 juta ton, tahun 2015 sebanyak 86 juta ton dan pada tahun 2016 tercatat 91 juta ton. Sampai saat ini ,pemanfaatan batubara di indonesia, baik untuk memenuhi energi maupun non-energi belum kompetitif dibandingkan minyak bumi masih terbatas hanya sebagai bahan bakar langsung (direct combustion) pada industri semen,industri -industri besi dan baja, pulp dan kertas, industri lain meliputi pabrik-pabrik tekstil, makanan, genteng, bata dan manufaktur serta 
sebagai energi panas dan bahan bakar pada pembangkit listeri (PLTU)serta keperluan ekspor. Selain ini, batubara juga digunakan dalam bentuk briket untuk memenuhi kebutuhan rumah tangga dan industri-industri kecil.

Walaupun Indonesia saat ini belum menerapkan teknologi pemanfaatan batubara seperti di negara-negara maju lainnya, tetapi diharapkan dimasa mendatang dapat mengembangkan teknologi pemanfaatan batubara yang dapat memberikan konstribusi bagi industri kimiadan petrokimia mengingat harga minyak bumi yang semakin naik dan jumlah cadangan minyak bumi yang semakin menipis seperti yang dinyatakan oleh Word Energy Council (WEC) pada tahun 2013 memperkirakan cadangan minyak bumi di dunia hanya cukup untuk 56 tahun kedepan.

Pemanfaatan batubara sebagai bahan bakar langsung dalam bentuk padatan bubuk dapat menimbulkan masalah lingkungan dari buangan padat yang berupa abu terbang (flyash). Oleh karena itu pemanfaatan batubara harus lebih ditingkatkan, salah satu cara yang cukup potensial dan dapat mengurangi dampak negatif terhadap lingkungan adalah dengan mengubah batubara menjadi bahan bakar yang ramah lingkungan. Teknologi yang dapat mengubah batubara menghasilkan bahan bakar gas, cair dan padat yang layak untuk dikembangkan adalah proses pirolisis. Pada proses pirolisis, batubara direngkahkan secara termik menghasilkan bahan bakar dalam bentuk cair, gas dan padat (char).Bahan bakar gas dan cair yang dihasilkan dari proses pirolisis batubara tidak lagi mengandung bahan pencemar sehingga saat digunakan sebagai bahan bakar tidak menimbulkan masalah pencemaran lingkungan akibat abu terbang.

Penelitian pirolisis batubara peringkat sub-bituminus dengan variasi temperatur dan ukuran partikel batubara bertujuan untuk mengkajidistribusi produk yang dihasilkan pada proses pirolisis terhadap produk gas, cair dan padat yang dapat digunakan sebagai bahan bakar alternatif pengganti minyak bumi.

\section{TINJAUAN PUSTAKA}

Batubara merupakan bahan bakar fosil padat yang terbentuk dari sisa tumbuh-tumbuhan yang tertimbun dalam waktu yang sangat lama dengan melalui beberapa fasa geologi. Tahapan pembentukan batubara dimulai dari kayu kemudian menjadi gambut, brown coal, lignit, su-bituminus, bituminus dan antrasit yang merupakan batabara peringkat tertinggi.Selama proses pembentukan terjadi penurunan kadar oksigen dan penurunan kadar zat terbang, sementara kadar karbon meningkat. Unsur-unsur pembentuk batubara adakah C, $\mathrm{H}, \mathrm{O}$ dan sedikit belerang dan abu.

Struktur kimia batubara sangat kompleks, sehingga sulit ditentukan, kira-kira berbentuk polimer padat yang tidak larut dalam pelarut organik. Struktur batubara tersusun dari gugus polisiklik dan aromatik, masing-masing gugus dihubungkan dengan struktur alifatik. Gugus polisiklik terdiri dari gugus fungsional oksigen, nitrogen dan sulfur. Pada proses pirolisis, struktir karbon tetap (fixed carbon) tidak terdkomposisi dan pada akhir proses sebagian besar menjadi kokas (Shinn, 1984).

\section{Prolisis Batubara}

Pirolisis batubara adalah proses pemanasan batubara dengan menggunakan gas inert $\left(\mathrm{N}_{2}\right.$ atau gas $\mathrm{He}$ ) atau dengan menggunakan pereduksi $\left(\mathrm{gas}_{2}\right)$. Pada pemanasan ini batubara terdekomposisi disertai dengan pemutusan ikatan, penguapan dan kondensasi yang berakibat terjadi perubahan densitas pada gugus alifatik dan aromatik. Produk dari proses pirolisis adalah gas, cair (tar) dan padat (residu) yang berupa arang (kokas) dan abu. Jumlah produk yang dihasilkan bervariasi bergantung pada beberapa faktor, misalnya temperatur operasi pirolisis, peringkat batubara, jenis gas inert, ukuran partikel. Jumlah residu yang dihasilkan kira-kira $50 \%$ dari berat batubara umpan (Suurberg, 1980). 
Keuntungan dari proses pirolisis adalah dapat dilakukan pada temperatur rendah dan tekanan atmosfer serta tidak memerlukan penambahan reaktan zat kimia, sedangkan kelemahan dari proses pirolisis , terutama untuk mendapatkan produk cair tidak semua peringkat batubara memberikan hasil yang memuaskan, hanya batubara peringkat tinggi yang dapat memberikan hasil yang baik. Proses pirolisis diategorikan berdasarkan suhu operasi, yakni ; Pirolisis temperatur rendah $\left(300-700{ }^{\circ} \mathrm{C}\right)$, pirolisis temperatur sedang $\left(700-900{ }^{\circ} \mathrm{C}\right)$ dan pirolisis temperatur tinggi $\left(>900{ }^{\circ} \mathrm{C}\right)$

Menurut Gavalas (1982) mengelompokan produk pirolisis batubara berdasarkan pada temperatur pembentukannnya. Kelompok pertama meliputi produk cair (tar), air dan gas karbon dioksida. Produk ini mulai dihasilkan pada temperatur $300{ }^{\circ} \mathrm{C}$ dan jumlahnya konstan sampai temperatur $700{ }^{\circ} \mathrm{C}$. Kelompok ke dua terdiri dari produk cair , gas $\mathrm{CO}$, gas $\mathrm{H}_{2}$ dan gas-gas hidroarbon (metana, etana, propana), produk ini terbentuk pada temperatur yang lebih tinggi dan jumlahnya terus meningkat dengan bertambahnya tinggi temperatur hingga $1000{ }^{\circ} \mathrm{C}$.

Menurut Owen (1979), jenis-jenis produk pirolisis pada temperatur rendah dan temperatur tinggi adalah sama, hanya berbeda kuantitasnya yakni terdiri dari produk gas, cair dan arang, produk cair terdiri dari tar, minyak ringan dan liquor. Produk liquor merupakan campuran dari amonium hidroksida dan amonium sulfat. Perbedaan yang mencolok antara produk pirolisis temperatur rendah dan temperatur tinggi adalah jumlah produk gas dan liquor tinggi, sementara produk tar dan minyak ringan menurun kira-kira $50 \%$

Menurut Van Heek,dkk (1993) menyatakan bahwa jumlah tar yang dihasilkan terus meningkat dengan kenaikan temperatur, tetapi pada temperatur $>600{ }^{\circ} \mathrm{C}$ sebagian senyawa tar terjadi perengkahan menjadi gas dan sebagian terdeposit menjadi karbon padat. Keaddan ini menyebabkan produk tar menurun dan produk gas meningkat tajam.

Hasildari berbagai penelitian yang terhimpun menunjukkan bahwa makin tinggi temperatur pirolisis, produk zat terbang meningkat, produk kokas menurun. Sementara Tyler, 1980; Collin, 1983; Calkins dan David, 1984; Teo \& Watkinson, 1986 menyatakan bahwa produk tar mencapai maskimum pada temperatur sekitar $550-600{ }^{\circ} \mathrm{C}$, sementara Linda Sayuti, dkk (2007), mengemukakan bahwa hasil cairan terbanyak didapat pada temperatur pirolisis $650{ }^{\circ} \mathrm{C}$ baik pirolisis termal maupun dengan menggunakan katalis, sedangkan pirolisis pada temperatur tinggi hasil terbanyak adalah gas untuk pirolisis termal, sedangkan pada pirolisis dengan menggunakan katalik $\mathrm{Ni}$ /zeolit adalah kokas.

Semakin besar ukuran partikel batubara, produk arang dan gas total meningkat, sedangkan produk cair (tar) berkurang hal ini dikarenakan ukuran partikel batubara yang besar menyebabkan pelepasan zat terbang keluar dari partikel memerlukan waktu yang lebih lama sehingga zat terbang berada di dalam partikel menjadi lama pula, kondisi ini menyebabkan sebagian tar mengalami perengkahan menjadi gas.(Stubington \& Sumaryono, 1984), hal yang sama juga dikemukkan oleh Caumia \& Kalkreuth, 1982, meneliti pengaruh ukuran partikel batubara, bahwa produk gas metan dan gas-gas hidrokarbon lannya serta gas-gas oksida bertambah dengan bertambahnya besar ukuran partikel batubara, hal ini menunjukkan terjadi peningkatan reaksi sekunder.

Pengaruh ukuran partikel batubara berpengaruh pada produk zat terbang total, ukuran partikel yang besar menurunkan produk tar dan meningkatkan produk gas, karena pengaruh reaksi sekunder lebih besar (Jianglong Yu, 2006).

\section{Mekanisme Pirolisis Batubara}

Reaksi pirolisis batubara merupakan proses yang sangat kompleks, selain struktur kimia batubara yang sangat rumit juga dipengaruhi banyak faktor, di antaranya temperatur, tekanan, ukuran partikel batubara, jenis dan asal batubara, laju gas inert laju pemanasan dan geometri reaktor.Model pembentukan produk pirolisis sulit untuk diketahui dengan pasti dan sudah banyak peneliti yang 
memperkirakan mekanisme reaksi pirolisis batubara menjadi produk gas, cair dan padat dari sudut pendekatan yang berbeda sehingga menghasilkan mekanisme reaksi yang bermacam-macam. Sejumlah peneliti mengemukakan bahwa mekanisme reaksi tidak terjadi secara serentak tetapi tahapan-tahapan. JF.Stubington dan Sumaryono, 1983 menjelaskan mekanisme proses pirolisis batubara melalui dua tahapan reaksi, yaitu reaksi kompetitif antara atom hidrogen dan atom oksigen dan reaksi sekunder yang terjadi pada senyawa zat terbang (volatile) .

Solomon, 1990 memperkirakan mekanisme pembentukan produk pirolisis dari struktur batubara melalui tahap reaksi primer dan reaksi sekunder yang ditunjukkan pada Gambar 1 . Menggambarkan struktur batubara yang terdiri dari senyawa siklik dan senyawa aromatik yang dihubungkan oleh jembatan alifatik dan gugus fungsional oksigen, nitrogen dan belerang.

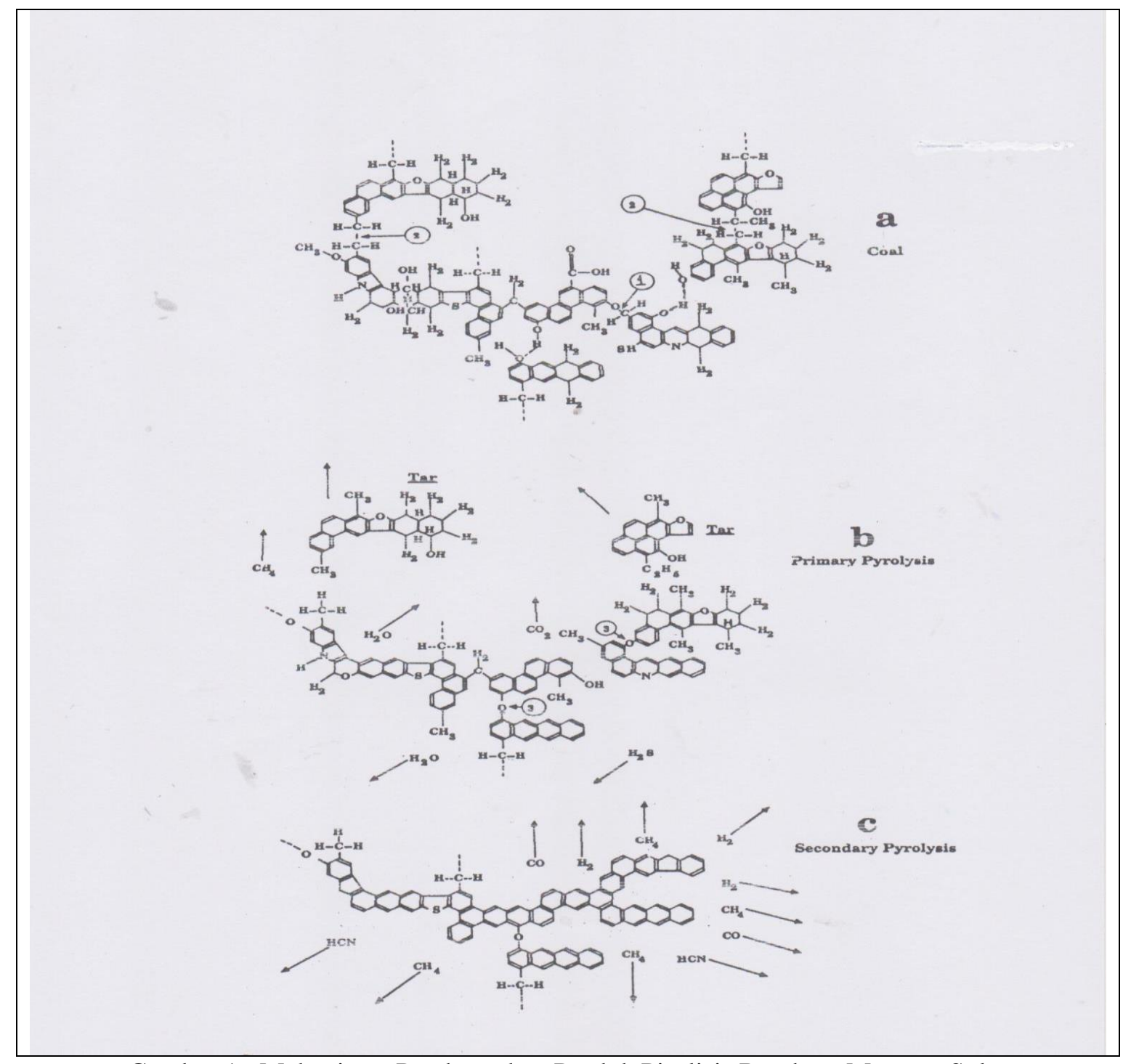

Gambar 1: Mekanisme Pembentukan Produk Pirolisis Batubara Menurut Solomon

Tahap reaksi primer terjadi pada temperatur $200{ }^{\circ} \mathrm{C}-400{ }^{\circ} \mathrm{C}$, proses ini dimulai dengan pemutusan jembatan yang paling lemah, yaknidekomposisi rantai alifatik dan gugus siklik pada ikatan C-C dan C-O (ditunjukan tanda 1 dan 2 pada gambar 1)senyawa pecahan - pecahan molekular atau radikal bebas diikuti dengan pelepasan atom hidrogen (Gambar 1.a)Sebagian atom hidrogen digunakan untuk menstabilkan radikal bebas membentuk senyawa yang lebih stabil dan menguap sebagai produk tar (Gambar 1.b label Tar). Sebagian radikal bebas terjadi polimerisasi menghasilkan senyawa dengan molekul yang lebih besar menghasilkan produk padat. Secara serentak juga terjadi 
reaksi dekomposisi gugus fungsional menghasilkan gas, terutama gas $\mathrm{CO}_{2}, \mathrm{CH}_{4}$ dan air. Gas metana terbentuk dari gugus metil yang terikat pada atom karbon aromatik kemudian bereaksi dengan atom hidrogen. Sedangan gas $\mathrm{CO}_{2}$ terbentuk dari kondensasi gugud karboksilat, sementara air terbentuk dari reaksi kondensasi gugus $-\mathrm{OH}$ dan guus $-\mathrm{COOH}$.

Tahap reaksi sekunder ditunjukan pada Gambar 1.C yang merupakan lanjutan dari reaksi primer, tahap reaksi sekunder terjadi pada temperatur $>600{ }^{\circ} \mathrm{C}$. sebagian produk berupa gas sebagai hasil perengkahan beberapa senyawa tar primer, di antaranya gas metana merupakan hasil perengakahan senyawa tar primer yang megandung gugus metil, gas karbon monoksida sebagai hasil perengkahan gugus eter dan gas hidrogen dihasilkan dari dekomposisi senyawa alifatik dan aromatik.

\section{METODA PENELITIAN}

Batubara yang dipirolisis peringkat sub-bituminus yang berasal dari Air Laya PT. Bukit Asam, Tanjung Enim, Sumatera Selatan. Penelitian dilakukan di Laboratorium Teknik Mesin Fakultas Teknik Universitas IBA. Proses pirolisis dilakukan dalam sebuah reaktor unggun tetap bervolume 4 liter. Batubara yang digunakan sebanyak $2,5 \mathrm{~kg}$ untuk sekali percobaan, ukuran partikel batubara divariasikan pada ukuran $-6 / 8$ mesh $(3,36-4,76 \mathrm{~mm})$ dan $-3 / 4$ mesh $(4,76-6,73 \mathrm{~mm})$ dengan laju alir gas Nitrogen tetap yaitu $300 \mathrm{ml} /$ menit. Penelitian dilakukan pada tekanan atmosfer, temperatur divariasikan dari $400^{\circ} \mathrm{C}$ hingga $700^{\circ} \mathrm{C}$

Rektor dilengkapi dengan termokopel yang ditempatkan pada bagian tengah reaktor untuk mengukur dan menjaga temperatur tetap konstan selama proses pirolisis. Proses pirolisis dilakukan dengan memanaskan batubara sebanyak $2,5 \mathrm{~kg}$ yang telah ditentukan ukuran partikelnya ke dalam reaktor melalui screw feeder sedikit-sedikit sambil temperatur operasi dijaga konstan. Produk cair dikondensasi di dalam tabung kondensor tiga tahap dengan menggunakan pendingin masing-masing air, air es dan air es + garam dapur. Produk cair ini merupakan campuran air dan tar, kemudain dipasahkan secara dekantasi.

Pengambilan sampel produk gas dilakukan setiap 15 menit dan dianalisis dengan gas kromatografi. Perhitungan konsentrasi gas dilakukan dengan menghitung luas kromatogram yang dihasilkan integrator. Batubara yang tidak terpirolisis merupakan produk arang yang tertinggal di dalam reaktor dan selanjutnya ditimbang. Rangkaian proses Pirolisis disajikan pada Gambar 2. 


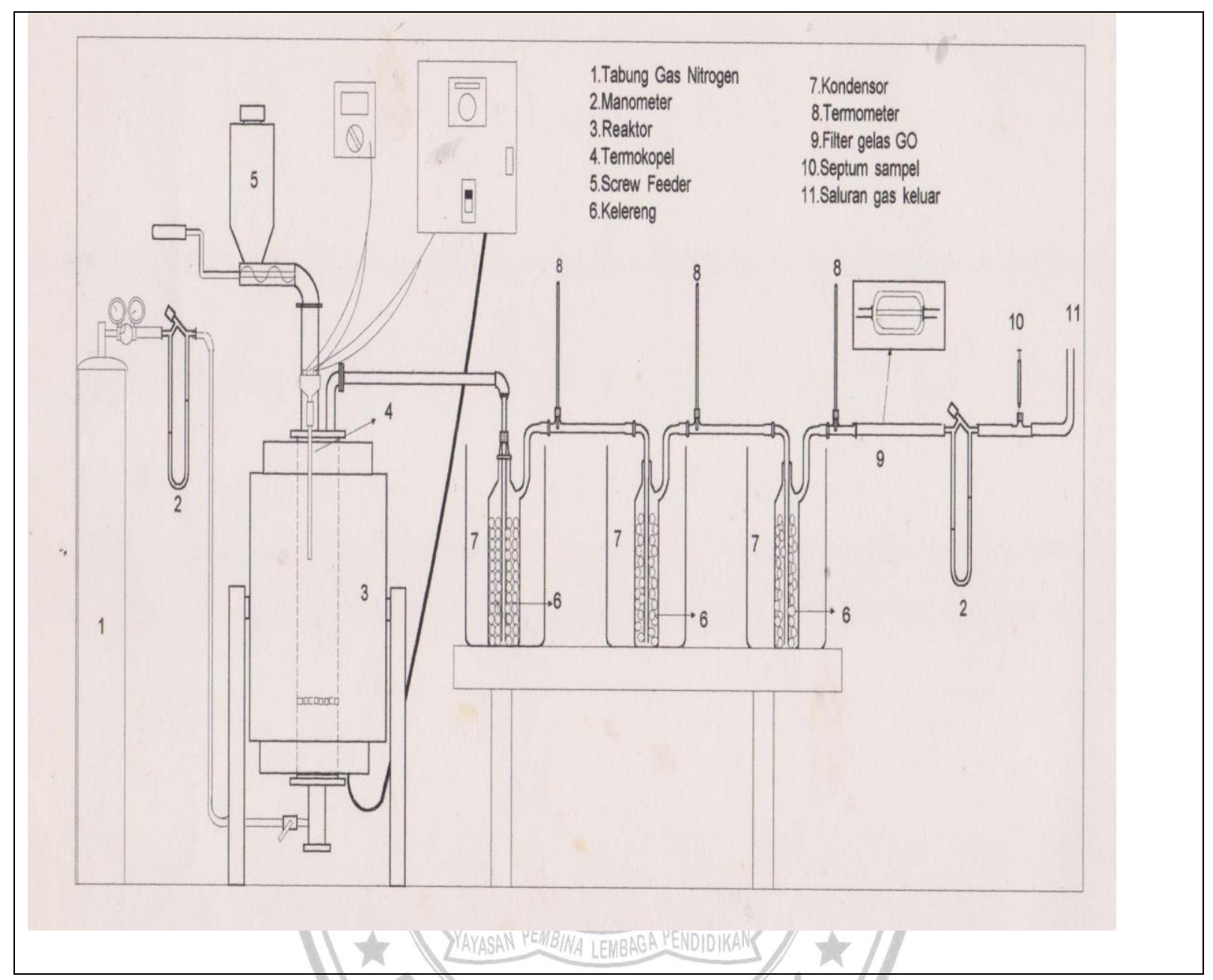

Gambar 2. Rangkaian Peralatan Pirolisis Batubara Bukit Asam

\section{HASIL DAN PEMBAHASAN}

Hasil penelitian mengenai pengaruh temperatur dan ukuran partikel batubara terhadap distribusi produk hasil pirolisis disajikan pada Tabel 1. dan Tabel. 2

Tabel 1. Hasil Pirolisis Batubara Sub-Bituminus B, ukuran parttikel -6/8 mesh

\begin{tabular}{lllllllll}
\hline \multirow{1}{*}{ Produk } & \multicolumn{8}{c}{ Temperatur ${ }^{\circ} \mathrm{C}$} \\
\cline { 2 - 9 } & \multicolumn{2}{c}{400} & \multicolumn{2}{c}{500} & \multicolumn{2}{c}{600} & \multicolumn{2}{c}{700} \\
\cline { 2 - 9 } & $\begin{array}{l}\text { Berat } \\
\text { gram) }\end{array}$ & $\begin{array}{l}\%- \\
\text { berat }\end{array}$ & $\begin{array}{l}\text { Berat } \\
\text { (gram) }\end{array}$ & $\begin{array}{l}\% \\
\text { berat }\end{array}$ & $\begin{array}{l}\text { Barat } \\
\text { (gram) }\end{array}$ & $\begin{array}{l}\%- \\
\text { berat }\end{array}$ & $\begin{array}{l}\text { Berat } \\
\text { (gram) }\end{array}$ & $\begin{array}{c}\%- \\
\text { berat }\end{array}$ \\
\hline Zat Terbang & 940,32 & 39,69 & 1024,35 & 43,84 & 1140,91 & 49,98 & 1254,69 & 53,79 \\
Gas & 214,62 & 9,06 & 267,45 & 11,45 & 300,31 & 13,16 & 412,39 & 17,68 \\
Tar & 194,80 & 8,22 & 202,20 & 8,65 & 228,90 & 10,03 & 193,30 & 8,29 \\
Air & 530,90 & 22,41 & 554,70 & 23,74 & 611,70 & 26,80 & 649,00 & 27,82 \\
Arang & 1429,00 & 60,31 & 1312,20 & 56,16 & 1141,80 & 50,01 & 1078,30 & 46,21 \\
Batubara yang & 30,68 & & 63,45 & & 117,29 & & 67,01 & \\
tertinggal di di & & & & & & & & \\
screw feeder & & & & & & & & \\
Total & 2369,32 & 100 & 2336,55 & 100,00 & 2282,71 & 100,00 & 2333,00 & 100,00
\end{tabular}


Tabel 2. Hasil Pirolisis Batubara Sub-Bituminus B, ukuran parttikel -3/4 mesh

\begin{tabular}{|c|c|c|c|c|c|c|c|c|}
\hline \multirow{3}{*}{ Produk } & \multicolumn{8}{|c|}{ Temperatur ${ }^{\circ} \mathrm{C}$} \\
\hline & \multicolumn{2}{|c|}{400} & \multicolumn{2}{|c|}{500} & \multicolumn{2}{|c|}{600} & \multicolumn{2}{|c|}{700} \\
\hline & $\begin{array}{l}\text { Berat } \\
\text { (gram) }\end{array}$ & $\begin{array}{l}\%- \\
\text { berat }\end{array}$ & $\begin{array}{l}\text { Berat } \\
\text { (gram) }\end{array}$ & $\begin{array}{l}\% \\
\text { berat }\end{array}$ & $\begin{array}{l}\text { Barat } \\
\text { (gram) }\end{array}$ & $\begin{array}{l}\%- \\
\text { berat }\end{array}$ & $\begin{array}{l}\text { Berat } \\
\text { (gram) }\end{array}$ & $\begin{array}{l}\%- \\
\text { berat }\end{array}$ \\
\hline Zat Terbang & 901,00 & 37,84 & 1008,90 & 42,14 & 1104,44 & 45,93 & 1243,65 & 52,93 \\
\hline Gas & 218,50 & 9,18 & 276,42 & 11,54 & 304,11 & 12,65 & 442,33 & 18,83 \\
\hline Tar & 171,70 & 7,21 & 172,68 & 7,26 & 193,53 & 8,05 & 168,52 & 7,17 \\
\hline Air & 510,80 & 21,45 & 558,80 & 23,34 & 606,80 & 25,23 & 632,80 & 26,93 \\
\hline Arang & 1479,90 & 62,16 & 1385,52 & 57,86 & 1300,17 & 54,07 & 1105,88 & 47,07 \\
\hline Batubara Umpan & 2500 & & 2500 & & 2500 & & 2500 & \\
\hline $\begin{array}{l}\text { BB yg tertinggal di } \\
\text { screw feeder }\end{array}$ & 119,10 & & 105,58 & & 95,39 & & 150,47 & \\
\hline $\begin{array}{l}\text { Total batubara yang } \\
\text { terpirolisis }\end{array}$ & 2380,90 & 100,00 & 2394,42 & 100,00 & 2404,61 & 100,00 & 2349,53 & 100,00 \\
\hline
\end{tabular}

\section{Pengaruh Temperatur terhadap Distribusi Produk Pirolisis}

Pengaruh temperatur operasi terhadap distribusi produk pirolisis dialurkan pada Gambar 3 dan Gambar 4 masing masing untuk ukuran partikel -6/8 mesh dan kuran partikel -3/4 mesh.

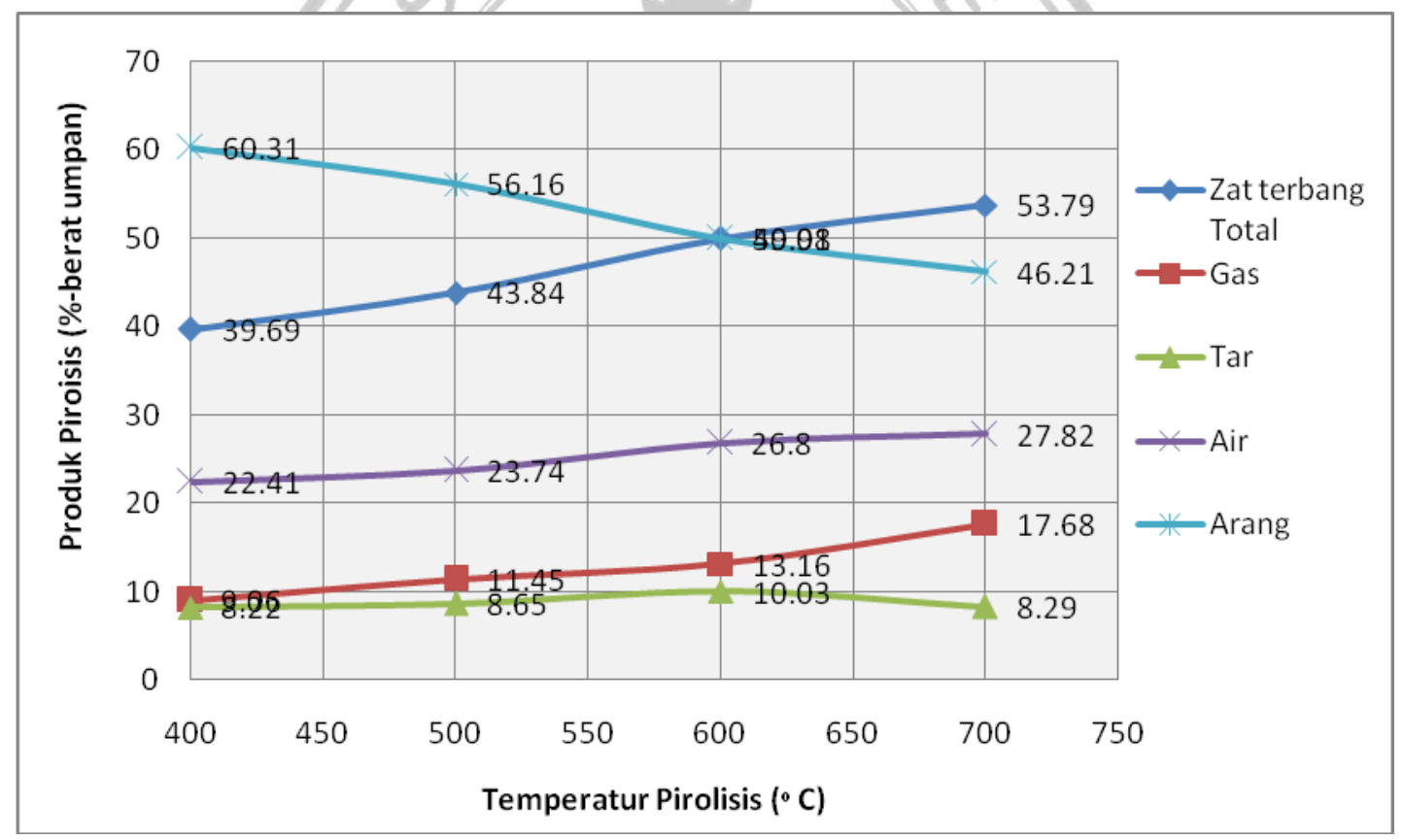

Gambar 3. Kurva Pengaruh temperatur terhadap Distribusi Produk Pirolisis Batubara SubBituminus B, ukuran Partikel -6/8 mesh 


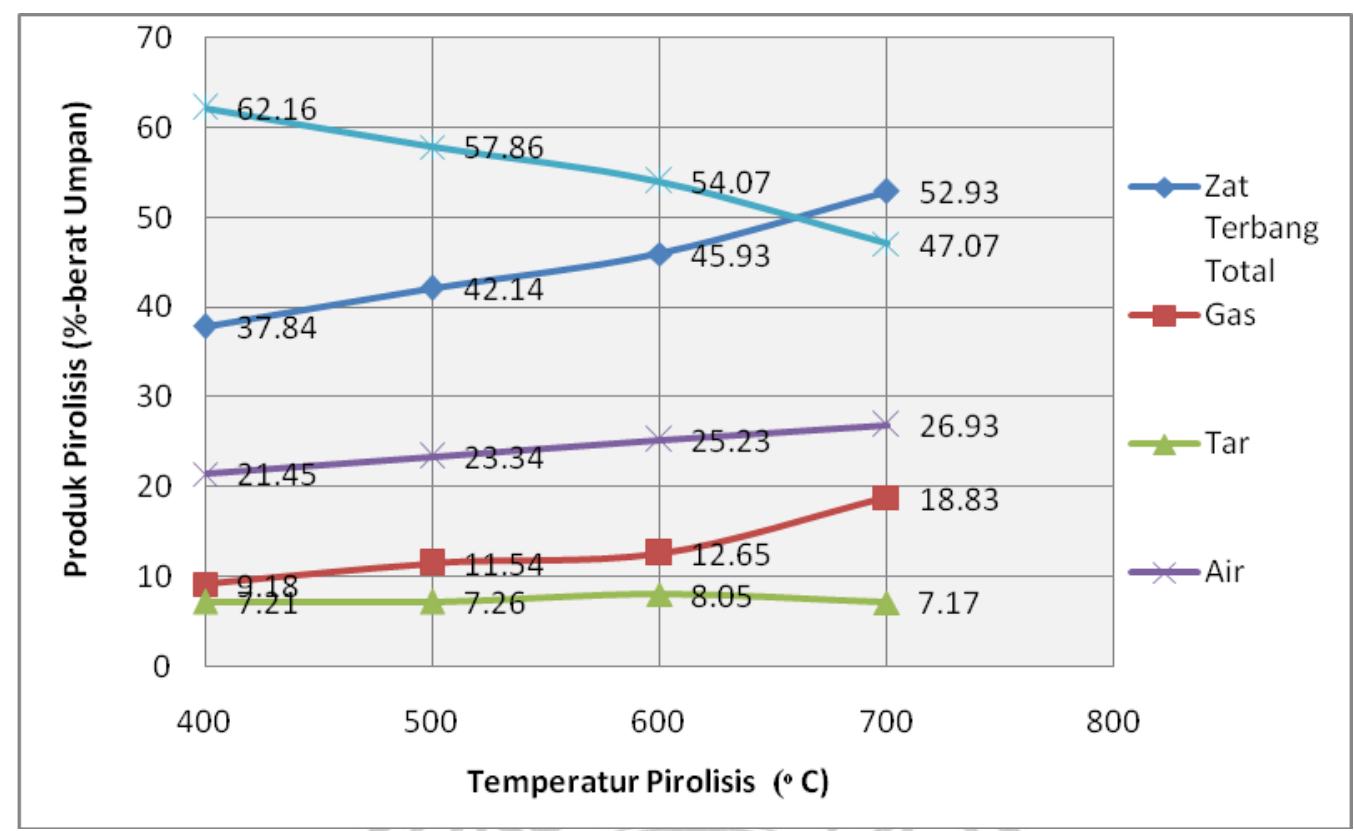

Gambar 3. Kurva Pengaruh temperatur terhadap Distribusi Produk Pirolisis Batubara SubBituminus B, ukuran Partikel -3/4 mesh

Dari Gambar 3 dan Gambar 4 menunjukkan bahwa produk zat terbang total meningkat dengan kenaikan temperatur, sementara produk arang berkurang dengan kenaikan temperatur hal ini mengindikasikan bertambahnya jumlah senyawa-senyawa yang dapat dibebaskan dari molekul batubara sebagai hasil perengkahan dekomposisi molekul batubara. Produk gas total dan air terus meningkat dengan kenaikan temperatur, sementara produk tar meningkat dengan kenaikan temperatur hingga mencapai maksimum pada temperatur $600^{\circ} \mathrm{C}$ kemudian menunjukkan penurunan pada temperatur $700{ }^{\circ} \mathrm{C}$.

Percobaan pada Temperatur $700{ }^{\circ} \mathrm{C}$ terlihat bahwa produk zat terbang total dan mencapai maksimum sementara produk tar dan arang menurun. Peningkatan produk zat terbang dikarenakan terjadi peningkatan produk air dan gas total sebagai akibat dari dekomposisi gugus fungsional menghasilkan gas terutama karbon dioksida, gas metana dan air, selain itu produk gas juga dihasilkan dari perengkahan senyawa tar primer.

Peningkatan produk tar dari temperatur $400{ }^{\circ} \mathrm{C}$ hingga suhu $600{ }^{\circ} \mathrm{C}$ disebabkan bertambahnya jumlah senyawa-senyawa tar yang dapat dibebaskan dari dekomposisi molekul batubara, pada interval suhu tersebut mekanisme pembentukan tar masih dalam tahap reaksi primer sehingga hasilnya selalu meningkat. Sedangkan pada temperaur $700{ }^{\circ} \mathrm{C}$, sebagian produk tar terengkah menjadi gas, keadaan ini menyebabkan produk tar menurun, hal ini menigindikasikan bahwa pada temperatur $700{ }^{\circ} \mathrm{C}$ tahap reaksi sekunder mulai berpengaruh. Kecenderungan ini sesuai dengan hasil penelitian yang dilakukan oleh Van Heek, dkk (1993)

Produk gas total dihasilkan secara simultan saat pembentukan tar primer yaitu dari dekomposisi senyawa alifatik dan gugus fungsional di antara jembatan metilen, gugus fungsional oksigen seperti gugus karboksilat, gugus hidroksil dan gugus eter. Pada temperatur $700{ }^{\circ} \mathrm{C}$ produk gas meningkat tajam karena sebagian besar dihasilkan dari perengkahan senyawa primer.Sementara produk air tampak meningkat dengan kenaikan temperatur,produk air sebagian dihasilkan dari reaksi esterifikasi dan kondensasi gugus hidroksil fenol, air yang terbentuk dari reaksi ini jumlahnya meningkat dengan kenaikan temperatur dan kuantitasnya bergantung pada jumlah oksigen yang terkandung di dalam batubara (Gavalas, 1982). 


\section{Pengaruh Ukuran Partikel terhadap Distribusi Produk Pirolisis}

Hasil penelitian pengaruh ukuran partikel batubara terhadap produk gas hasil pada rentang temperatur $400 \mathrm{~s} / \mathrm{d} 700{ }^{\circ} \mathrm{C}$ disajikan pada Gambar 4 dan Gambar 5

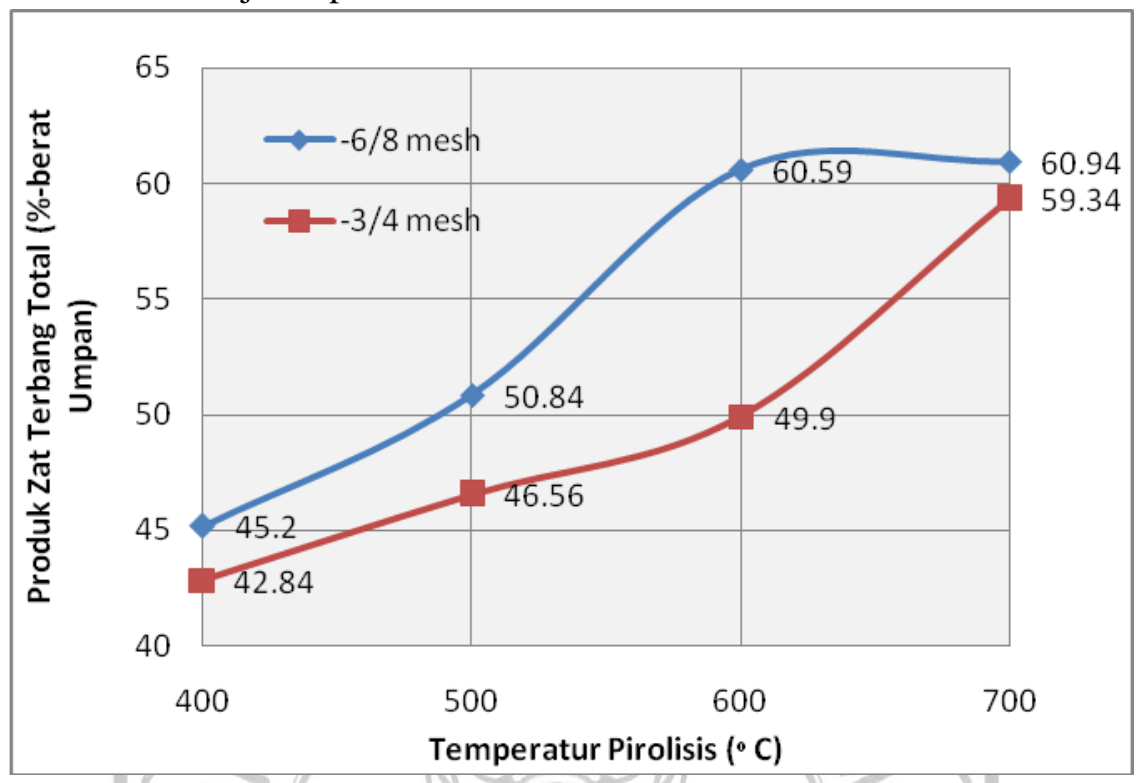

Gambar 4 : Kurva Pengaruh Ukuran Partikel Terhadap Produk Zat terbang Total
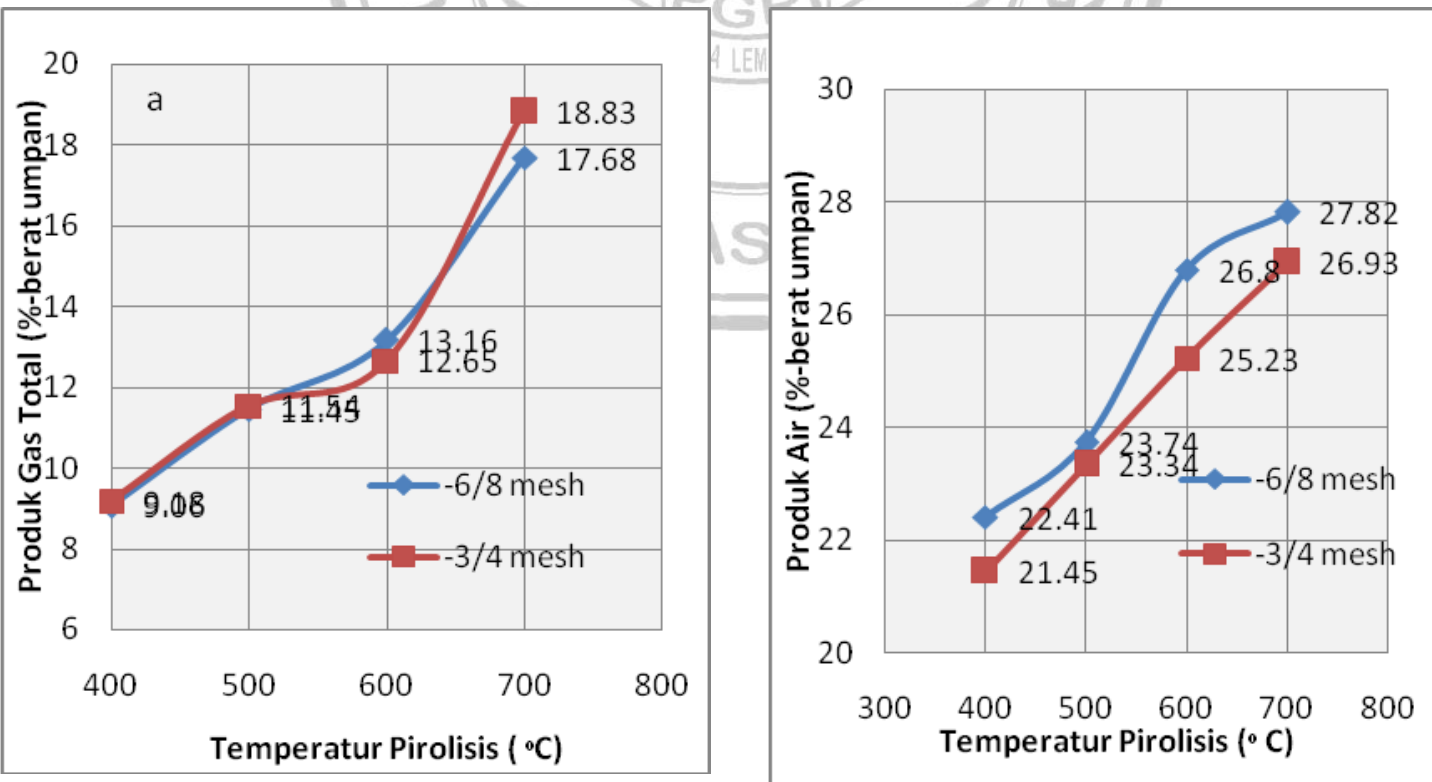


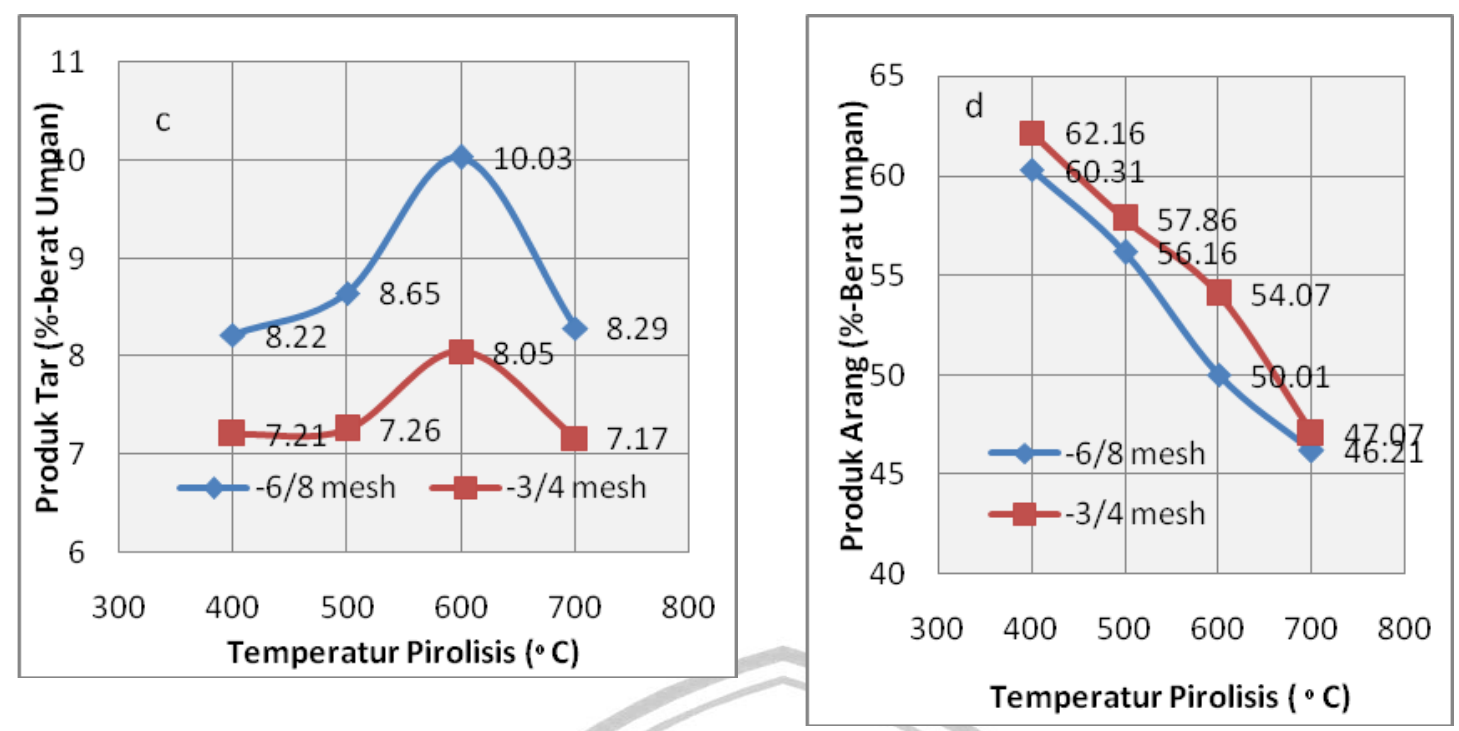

Gambar 5 : Kurva Pengaruh Ukuran Partikel Batubara Terhadap Distribusi Produk gas, tar, air dan arang

Hasil penelitian menunjukkan bahwa pengaruh ukuran partikel terhadap distribusi produk hanya berpengaruh pada temperatur $400 \mathrm{~s} / \mathrm{d} 600^{\circ} \mathrm{C}$.Pada interval termperatur tersebut pada ukuran partikel yang lebih kecil (-6/8 mesh), produk zat terbang total dan tar lebih tinggi dibanding pada ukuran partikel yang lebih besar ( $-3 / 4$ mesh) , sementara produk arang bertambah dengan bertambahnya besar ukuran partikel, sedangkan gas hampir tidak berpengaruh. Fenomena ini menunjukan bahwa pada ukuran partikel yang lebih besar distribusi panas tidak sebaik pada ukuran partikel yang lebih kecil, panas tidak terdistribusi sampai ke dalam partikel, sehingga reaksi perengkahan tidak sempurna, akibatnya zat terbang yang dapat dibebaskan menjadi produk tidak sebanyak pada ukuran partikel yang lebih kecil.

Selain itu, karena ukuran partikel yang besar, menyebabkan pelepasan produk zat terbang total dari dalam molekul batubara ke luar partikel memerlukan waktu yang relatif lebih lama sehingga memungkinkan terjadi reaksi sekunder internal yang berupa perengkahan tar yang belum keluar dari partikel menjadi fraksi yang lebih ringan (gas) atau terjadi polimerisasi menjadi molekul yang lebih besar dan juga terjadi deposit karbon menjadi kokas, hal ini terlihat dengan meningkatnya produk arang pada partikel yang lebih besar (-3/4 mesh). Hasil penelitian ini sesuai dengan yang dinyatakan oleh Suurberg, dkk (1980), Gavalas, dkk (1982) dan Stubington dkk (1984) menyatakan bahwa ukuran partikel batubara yang besar menyebabkan produk tar berkurang, sementara Yu (2006) menyatakan bahwa reaksi sekunder akan meningkat bila digunakan ukuran partikel batubara yang lebih besar karena semakin besar resistensi zat terbang keluar dari dalam partikel batubara.

\section{KESIMPULAN}

1. Temperatur Pirolisis sangat menentukan distribusi produk pirolisis, Kenaikan temperatur pirolisis, produk zat terbang total meningkat, sementara produk arang menunjukkan penurunan, sedangkan produk tar menunjukkan kecenderungan meningkat dari temperatur $400^{\circ} \mathrm{C}$ sampai $600^{\circ} \mathrm{C}$, diatas temperatur tersebut cenderung menurun. Produk tar mencapai maksimum pada temperatur pirolisis $600{ }^{\circ} \mathrm{C}$ yaitu $10,03 \%$-berat untuk ukuran partikel $-6 / 8$ mesh dan 8,05 \%-berat untuk ukuran partikel $-3 / 4$ meshProduk gas menunjukkan kecenderungan meningkat dengan bertambah tinggi temperatur hingga temperatur $700{ }^{\circ} \mathrm{C}$ 
yaitu sebesar 17,68 \%-berat dan 18,83\%-berat masing-masing untuk ukuran partikel $-6 / 8$ mesh dan $-3 / 4$ mesh

2. Pengaruh ukuran partikel batubara menunjukkan bahwa produk zat terbang total dan tar menurun dengan semakin besar ukuran partikel batubara. Produk zat terbang maksimum diperoleh pada ukuran partikel -6/8 mesh sebesar 53,79\%-berat pada temperatur pirolisis 700 ${ }^{\circ} \mathrm{C}$,. Sedangkan produk tar menurun dengan bertambah besar ukuran partikel, sementara produk arang meningkat dengan semakin besar ukuran partikel batubara yaitu sebesar 60,31 $\%$ dan 62,16 \% masing-masing untuk ukuran partikel -6/8 mesh dan -3/4 mesh pada temperatur pirolsis $400{ }^{\circ} \mathrm{C}$. Pengaruh ukuran partikel terhadap produk gas menunjukkan hasil yang relatif tidak signifikan

\section{DAFTAR PUSTAKA}

Collin,P.J, dkk,1983. Structural Characterization of Coal Tar Derived by Flash Pyrolysis. Coal Liquefaction vol.1 Edited by Schulz, Jhon Willey \& Son, New York.

Gavalas,G.R.1982. Coal Pyrolysis, Coal Science and Technology 4”. Elsevier Scietific Publishing Co, New York

https://finance.detik.com/infografis/d-3417754/ri-punya-cadangan-batu-bara-24-miliar-ton-yangmasih-perawan

Heek Van,K.H dan Hodek, W. 1993. Structure and Pyrolysis Behaviour of Differents coals and Relevant Model Subtances. Fuel.73.886-896

Syafira Primadita, CNN Indonesia, diakses Rabu, 21/03/2018 19:41

Sayuti,L. dkk, 2007 Perengkahan Produk Cair Batubara Dengan Katalis Ni/Zeolit, J.Kim,Sains \&Apl. Vol.X.No.1, hal.,7-11

Shinn,J.H. (1984). From CoalTo Single-Stage and Two-Stage Product : a Reactive Model of Coal Structure, Fuel, 63,1187-1195.

Solomon, P.R.dkk. 1992.Coal Pyrolysis Experiment Kinetic Rates and Mechanism. Prog/Energy Combust Sci,18,133-220.

Stubington,Jhon,F,Sumaryono. 1984. Release of Volatiles From Large Coal Particle in a Hot Flusized Bed. Fuel,63,1013-1019

Suurberg, E.M. dkk,(1980) Product Compositional in Rapit Hydropyrolysis of Coal, Fuel,59, 405-412 Yu Jainglong; Lucas, Jhon A;Wall.Terry F. 2006 Formation of the structure of Chars during devolation of pulveredand its thermoproperties; A review Elsevier 